\title{
The Green Campus is also a Virtual One
}

\author{
Dr John Blewitt \\ Sustainability and Knowledge Transfer Co-ordinator \\ School of Geography, Archaeology and Earth Resources \\ University of Exeter, UK \\ Email: J.D.Blewitt@exeter.ac.uk
}

\begin{abstract}
Purpose- to discuss the role and potential of digital media in education for sustainability. Design/methodologylapproach- the paper analyses the role of education for sustainability as enabling future sustainability practitioners to become key change agents and leaders in various fields of activity. It is important that generic skills and understandings are married to a capability to lead beyond the disciplinary or professional authority provided by any one specific education or institutional commitment. This means that "academic" education for future (and current) sustainability professionals needs to focus on capabilities and leadership, transdisciplinary research, new media technologies and e-learning.

Findings- new media ecologies are raising important questions about the nature of experiential learning and what it means when we talk of "living sustainability". With reference to various developments in e learning including the European Union's aim to establish a Virtual Campus for a Sustainable Europe it is important to understand that elearning and the digital environment is part of our experiential lifeworld on and off campus. Practical implications- sustainability practitioners need to fully explore the potential that new media technologies offer in connecting people to place, to each other and to the need transdisciplinary inquiry and pedagogy within the university.

Originality/value- the issue of new media in education for sustainability is rarely discussed by environmental educators and as such is under theorized and its potential largely ignored.
\end{abstract}

Keywords: New Media, Higher Education, Sustainability, Leadership.

Paper Type: conceptual

\section{Introduction}

Within the growing number of professional educators focusing on sustainability it is generally accepted that no one disciplinary perspective offers the key to understanding our present problems or anticipated future ones. Although it may be possible to agree on some basic values for policy formation, principles for research and even on practical action, implementation often requires consummate skill, endless patience and an unrealistic timescale and if the recent reports emerging from the scientific community studying climate change are largely true, time is clearly running out (Hansen et al, 2008). For activists and writers like Bill McKibben and founder of the 350ppm (http://www.350.org) movement "urgency" hardly seems appropriate. The range of values informing global and local discussions encompass the esoteric, spiritual and deep green to the strictly technicist where ecological modernizers become dazzled with the fixes advocated by geoengineers, synthetic biologists and nanotechnologists (Schneider, 2008). There may be, as the Canadian political scientist Thomas Homer-Dixon (2002) argues, an 
ingenuity gap waiting to be filled but in the meantime it is clearly important to accomplish something more inspiring than wishful thinking. Entering into a constructive and productive dialogue of values and practices can be facilitated by a sensitive application of much criticized, unscientific, vague and woolly concept of sustainable development. As Blake Ratner (2004: 62) writes,

The sustainability concept is meaningful, therefore, not because it provides an encompassing solution to different notions of what is good, but for the way it brings such differences into a common field of dispute, dialogue, and potential agreement as the basis of collective action.

Similarly, Cairns $(2003 ; 2004)$ views sustainability as extremely complex, warning that scientific uncertainties must not be simplified to the degree many decision makers in business and government would prefer. Strategies for sustainability must be ethically grounded in a language and literacy consonant with the organizational level or geographical locality people inhabit. They need to be both top down and bottom up. Processes of effective communication, social learning and leadership need to emerge prefiguring a paradigm shift in higher education thought and action (Sterling, 2001). Knowledge, and ultimately wisdom should not be separated from practice or confined to disciplinary or professional silos. Just as climate scientists work with insurance agents and politicians, and consumers ask where all the stuff they buy comes from,urban planners work with community activists as well as quantity surveyors, architects and economists, so the world's complexity has been made manifest in a whole host of multi agency partnership workings, problem identification seminars and transdisciplinary research projects, knowledge creation and transfer practices. Sustainability education needs to foster what Gibbons (1994) and his colleagues refer to as Mode 2 knowledge which is heterogeneous, flexible, dynamic, non-hierarchical, socially accountable and reflexive.

There are clear signs that campuses and curricula are changing (Barlett \& Chase, 2004; Gough \& Scott, 2008) but the question remains whether or not "sustainable education", that paradigm shift in educational values and perspectives, has gained sufficient purchase within the sector to effect the revolution necessary to enable present and future generations of students to act wisely, co-operate rationally, inquire socially and engage publicly. As Maxwell (2007) argues academic inquiry needs to operate as if it were the people's civil service but to do this it must first address its own structural irrationality which sees the public as something to be studied rather than as people to be helped. Likewise, Selby (2007) stresses the urgency of our global predicament seeing the role of higher education as needing to prepare us for contraction. Climate change, excessive resource use and overpopulation requires formal and informal education to help nurture alternative and localized conceptions of the "good life" together with more holistic ways of mediating and interpreting reality. Higher education learning needs a keener appreciation of complexity - the multiple ramifications and reverberations of human action. Selby recognizes the inherent complacency in the view that the academy is only for disinterested contemplation and reflection. It is that certainly but it needs to do more than monitor our demise.

So, if contraction is to be the axial principal of a wiser higher education this will necessarily involve dematerialization, new pedagogies and undoubtedly an enhanced role for new media technologies, e-learning, pervasive and sustainable computing (Mocigemba, 2006). As the Mckinsey report, SMART 2020: enabling the low carbon economy in the information age concluded (GeSI, 2008: 10-11), 
The scale of emissions reductions that could be enabled by the smart integration of ICT into new ways of operating, living, working, learning and traveling makes the sector a key player in the fight against climate change, despite its own growing carbon footprint. No other sector can supply technology capabilities so integral to energy efficiency across such a range of other sectors or industries.

The McKinsey report identifies key areas where this can occur - logistics, building and production. Computer companies like Sun Microsystems have developed "thin client" software which has low environmental impacts. JISC (J oint Information Systems Committee), an independent advisory body to Further and Higher Education in the UK, recently launched SustelT (http://www.susteit.org.uk/index.php) - a major research and development project investigating low carbon computing for the higher education sector. Indeed, sustainable computing is no longer the oxymoron critics have claimed for new digital media is facilitating the development of intelligent campuses, e- and blended learning and a more efficient and effective utilization physical space. A study by the UK's Open University (Roy, Potter, Yarrow \& Smith, 2005:4) concluded that online distance learning courses consumed nearly $90 \%$ less energy and produced $85 \%$ fewer $\mathrm{CO}_{2}$ emissions (per student per 10 CAT points) than conventional campus-based university courses. The university needs realize the sustainable principles informing other developments like the ecopolis where green architecture, social connectivity, renewable energy, smart technology, ecodesign and environmental learning emerge from a diversity of natural ecologies (Register, 2006).

\section{Education - Sustainability - Leadership}

The dynamic nature of complexity and emergence means massive challenges face everyone in adapting to, and adopting, the skills, capacities and capabilities of learning to deal with intellectual uncertainty and of acting and leading beyond the conventional boundaries of disciplinary and professional authority. As our knowledge increases the scope of what is unknown increases too and only the capacity to think and act wisely offers opportunities for a creative engagement with the fundamental imperatives of global warming, the international credit crunch, environmental limits of the megacity and the affordances of new digital technologies. Everything is connected but in ways we do not, and perhaps cannot precisely, know. Global level structures, or patterns, evolve from local level interactions and from relatively simple rules. "Complex adaptive systems" are characterised by both a high degree of interaction and the way the system is itself organised with outcomes not linearly related to initial conditions (Mihata, 1997).

Sustainable education and leadership must address these challenges.

Julia Middleton (2007), founder and chief executive of the leadership organization Common Purpose, argues that virtually everywhere conventional distinctions are dissolving. Traditional forms of authority are becoming less clear cut and relevant although many leaders (and educators) continue to focus on prescribed responsibilities that prevent them from seeing and understanding the wider picture making them very vulnerable for they are frequently blind to potential threats, difficulties or opportunities as they appear on the horizon. For Middleton, leaders need to recognize the value of diverse networks which extend beyond their zones of proximity, familiarity and competence. In new unfamiliar circumstances, they must rely on influence rather than power, and dialogue rather than direction. By working in "the outer circles" leaders can detect those small but significant changes that may sooner or later impact seriously on their designated sphere of influence, control and responsibility. In the complex, complicated, changing, connected, uncertain 
and information saturated digital world, it is easy to become dazzled and suspicious in turn. The promotional videos for Ohio and Texas State virtual campuses confidently claim that digital technologies and virtual worlds such as Second Life offer networks that may shape new communities of learning, exploration and practice. The AASHE (Association for the Advancement of Sustainability in Higher Education) joined the Virtual Energy Forum in June 2008 where users could engage with virtual booths, exhibition stands, watch high quality videos and participate in live discussion (http://www.virtualenergyforum.com/about us.php).

New media technologies are clearly changing the nature of learning, of educational opportunity, creative thinking and the meaning of literacy. Birkerts (1994) fears the death of the book, of linear and logical argument and erosion of attention spans longer than 30 seconds . However, the number of books and (academic) journals published electronically increases yearly and for David Weinberger (2002), the web may be distracting, composed of small pieces loosely joined, but perhaps distraction represents our capacities finally finding the form that suits it best. Sustainability educators need to access information from many sources and they need to synthesize this data and collaborate with others to create knowledge from it. Acknowledging the work by Pierre Levy (1997), the media theorist Henry Jenkins (2007) expertly outlines the participatory affordances of Web 2.0 and the wiki phenomenon which may offer a hidden curriculum of collective intelligence, judgement, networking and negotiation in a new sustainable education. There are already many sustainability/higher education wikis ( http://sustainability.mit.edu/Main Page; http://erdt.plymouth.ac.uk/csfwiki/index.php/Main Page) and perhaps the university of the future will be a virtual learning environment that may also include a number of physical campuses in many nations.

The European Union's (EU) project to establish a Virtual Campus for a Sustainable Europe (VCSE) is an ambitious plan aiming to connect fifteen European Universities in a collaborative venture enabling EU citizen's to study a variety of sustainability focused modules. Students will fashion the content their own learning by electing to study simultaneously in different places while remaining in one or moving through many. This new digital world affords enhanced opportunities for choice, flexibility, mobility, personalized and collective learning. Of its numerous anticipated outcomes three are particularly important:

- $\quad$ Virtual mobility between students, technical and academic staff of partners' universities

- Virtual mobility between local "actors" on sustainability issues (local/regional "elearning networks")

- Information dissemination and sensitization of general public by the partners' universities

The digital world is clearly as real as the grass that grows under your feet and where the two come together an educational ecotone emerges - a rich transition zone between two dissimilar ecosystems creating a potential habitat with a large degree of cultural diversity and intellectual health. With information growing by the second, knowledge expanding exponentially and wisdom still in short supply, applying new digital technologies to the sustainability imperative, requires a transdisciplinary synthesizing mind and a higher educational specialism that helps students to become generalists. As Gardener (2007) argues in his Five Minds of the Future, the most precious syntheses will involve some 
courageous creative leaps of imagination and recognition. We now need to live, work and study in dematerialized as well as non material worlds. Touching the digital world is one aspect sustainable learning and literacy and this can only come with reflection, wisdom, enterprise and some humility.

\section{Digital Ground}

Many leadership tools, sustainability practices and learning capabilities involve interacting with both digital and physical environments. Computer and video games are persuasive instruments for learning and literacy as Gee (2003) has argued. Collaborative virtual reality projects like Virtual Harlem have created learning environments that have enriched student understanding of history, culture, identity, race and place by being able visit a digitized Harlem Renaissance of the 1920s and 1930s. In a paper discussing a semester-long user study conducted by the Central Missouri State University and the University of Illinois at Chicago, Park et al (2001) argue that the students' virtual learning experiences stimulated increased real time and real world engagement in the subject matter with participants wanting more exposure to the new media technologies in their future learning. Similarly, my own experience running the MSc Sustainable Development at the University of Exeter, where a number of modules use a Webct virtual learning environment, students quickly achieve a sophisticated new media literacy and capability that renders more traditional modes of stand and deliver teaching redundant. Student module evaluations are invariably enthusiastic with sophisticated VLEs and virtual staff student liaison committees becoming an expectation not a novelty.

This experience has been mirrored by the popular and critical reception of more commercially orientated products. Designer Will Wright's SimCity has an overt and engaging educative purpose. SimCity, and related games, run on relatively low end home computers with implication being as significant as simulation for SimCity creatively draws on the existing urban knowledge and understanding of the players themselves. Andrew $\mathrm{C}$. Revkin (2007) in his "dot earth" blog for the New York Times argues, with the aid of an attractive promotional video clip, that players of the latest, more sustainability conscious, SimCity have the opportunity of creating a virtual ecopolis even if the energy scenarios have been designed courtesy of Beyond Petroleum. He writes,

My initial impression is that this game could expose more Americans to the realities of the climate-energy challenge (and opportunity) than another big science report.

and later ...

One reason is that the game, while very much entertainment, forces players (...) to make choices, to understand that forswearing coal means installing an amazing number of much more expensive wind turbines and solar panels.

That means that to avoid going broke fighting the climate fight, one has to invest a lot more to make energy storage and solar panels far, far cheaper - and such research still isn't happening on anything close to the scale scientists say is needed.

But the game also shows the long-term consequences of sticking with the cheap and easy fuel of the last two centuries - black combustible rocks. 
For gamers who build a city around fossil energy choices, droughts and heat waves supposedly intensify (...). As the producer, Rachel Bernstein, explained, climaterelated disasters abroad also have a ripple effect that hurts your imagined city's economy. And on and on.

Many reviewers have equally high regard for Wright's new game, Spore, which addresses the biological processes of life itself (http://eu.spore.com/whatisspore/index.cfm) and games such as Food Force available from the United Nations World Food Programme (http://www.food-force.com/) effectively articulates players as Development Studies students and global citizens. Greenpeace's internet based Efficiencity (http://www.greenpeace.org.uk/files/efficiencity/index.html) and even Chevron's Energyville (http://www.willyoujoinus.com/Energyville/) invite players to build their own ecocity and such learning experiences could easily be adapted so that faculty and students could virtually build an eco-campus and, in so doing, recognizing where existing structures and processes fall short. The University of Toledo in Ohio, which has an extensive on line distance learning provision, also hosts a publicly available interactive web resource called Virtual Insight of a Sustainable Building Model

(http://www.utoledo.edu/ucollege/ced/cci\%20website/EACT\%20Incubator/Sustainable\%20 Building\%20features.html) where users may collect information on various energy efficient technologies and eco building materials that may be incorporated into residential, commercial, office and other buildings with the aim is to improving comfort and promoting environmental sustainability. Digital conservation enables much of the world's intangible (and tangible) cultural heritage to be accessed across social, cultural, spatial, institutional and generational boundaries (Parry, 2007).

E-learning is increasingly becoming an important element of the higher education student experience whether they study on campus and attend face to face seminars and lectures or study at distance. The laptop on the lawn or in the cafe-bar is a familiar sight. In the age of pervasive computing, of smart technology and smart buildings, of ipods and iphones, of mobile banking and computer generated imaging, of wifi zones that cover whole towns let alone university buildings, the digital non material world is an inevitable and increasingly "natural" aspect of our living and being in the world. New media technologies offer not simply text based or predominantly visual experiences but ones which are truly multi dimensional. Just as we make meaning through our bodily experiences we physically experience digital media. As we interact with them we make sense of the buzzes and vibrations of the cell phone, the haptic (touch sensitive) technologies that clunk or click as our mouse glides over specific icons. We may become immersed in a 3D virtual environment or even experience the "biorhetoric" transformations envisaged in Kirstie Fleckenstein's (2003) attempts to fuse semantics with materiality, embodying literacy through imagery, which create new metaphors or "imagewords". GPS technologies may literally speak to us and GIS images and infrared imaging enable us to see what normally cannot be seen. As Paterson $(2006,2008)$ has argued haptic technologies can enable users to feel objects over a distributed network giving rise to many possibilities for experiential, sensual and situated learning. In 2001 a "Smell Personal Scent Synthesizer" prototype was developed by DigiScents. Whatever next?

In an interesting case study of a postgraduate induction programme that married elearning with experiential learning and drew explanatory power from the visual metaphor of a combination lock, Beard, Wilson and McCarter (2007:13) conclude,

It can be argued that e-learning attempts to imitate or complement genuine learning 
experiences whether from the real world or the classroom. Thus e-learning, by definition, will always be a mediated form of real experience and therefore might never be fully equivalent to direct experiential learning. For this reason e-learning is, in certain respects, a quest for the 'Grail' - always an objective, but unlikely to be fully achieved.

Yet, by drawing upon the elements of the wider environment, learning activities, multisensory exposure, emotions and forms of intelligence depicted in the learning combination lock, e-learning design can offer learners more holistic learning support.

Consequently, the digital ground of sustainability education must not be dismissed as some sort of techno-geek diversion that deforms learning and distorts the quest for a more sustainable future. Mocigemba (2008) and Blewitt (2008) both show that digital communications can strengthen participation, deliberation, transcultural learning and so contribute to a clearer understanding of what sustainability means to many different people. McCullough (2004) shows that although disembodiment may make us more receptive to the virtual, interactive design can shape our desire and ability to connect to the places we inhabit. The digital world is not a parallel world - it is one we actually live in and smart spaces recognize what is going on within them and respond to what we do. The excellent BREEAM or LEED rated campus building designed to be adapted as it ages is also part of this holistic learning environment. In Design on the Edge, David Orr (2006) discusses the model ecological design of The Lewis Center at Oberlin College. It is a story of hard won institutional change and the importance of green design in creating opportunities for formal and informal learning, creative leadership and direct experience of sustainability in action. The Lewis Centre may be physically located on an actual physical campus in the United States but it may be experienced from afar via photogalleries, interviews, webcams and a virtual tour (http://www.oberlin.edu/ajlc/ajlcHome.html).

\section{Conclusion}

We quickly become attuned to noise, ugliness, nonsense, change, false tradition, polluted air, ignorance and disinformation and when this happens our senses and sensitivities become dulled. All our senses are engaged in the day to day encounters of our numerous life worlds - the supermarket, the park, the green university campus and the ipod. These designed and natural objects speak to all our senses in combination, rarely in isolation. As Abram (1996) writes, neither the perceiver nor the perceived is totally passive in this relationship even though when we conceptualize our experience we sometimes repress our sensuous involvement, our participation, in the world. Too frequently our conceptualization of the digital world ignores this sensuous engagement and the many affordances it offers to fashion a more sustainable educational experience. New media technologies are more than utilitarian commodities lacking souls, dehumanizing us at every opportunity by distancing us further from that illusive dream of nature. These technologies are now constitute a great deal of learning and everyday living. New media culture is shared by people of all ages and virtual reality scenarios and smart buildings touch us just as we can literally and metaphorically touch them. The WorldWideWeb has put the world at our fingertips and this in turn is changing our perception of that world, the ways we relate to and learn about it. But we do live in the physical world and the physical university campus will, and should not, disappear. It is becoming both a place and a space, a real and virtual world where people congregate, connect, communicate, learn and maybe even fly.

Don't log off yet - you're living sustainability. 


\section{References}

Abram, D. (1996) The Spell of the Sensuous. Vintage Books, New York.

Bartlett, P.F. \& Chase, G.W. Eds (2004) Sustainability of Campus: stories and strategies for change. MIT Press, Cambridge Mass.

Beard, C. M., Wilson, J.P., \& R. McCarter (2007) Towards a Theory of e-Learning: Experiential e-Learning, Journal of Hospitality, Leisure, Sport and Tourism Education, Vol.6, No. 2, pp3-15.

Birkerts, S (1994) The Gutenberg Elegies The Fate of Reading in an Electronic Age. Faber, London.

Blewitt, J. Ed (2008) Community, Empowerment and Sustainable Development. Green Books, Totnes.

Cairns Jr, J. (2003) Integrating top-down/bottom-up sustainability strategies: an ethical challenge. Ethics in Science and Environmental Politics. Available at: http://www.intres.com/articles/esep/2003/E26.pdf

Cairns Jr, J. (2004) Future of Life on Earth. Ethics in Science and Environmental Politics. Available at: http://www.int-res.com/articles/esep/2004/E41.pdf

Fleckenstein, K.S. (2003) Embodied Literacies: Imageword and a Poetics of Teaching. Southern Illinois University Press, Carbondale.

Gardner, H. (2007) Five Minds for the Future. Harvard Business School Press, Boston.

Gee, J.P. (2003) What Video Games Have To Teach Us About Learning and Literacy. Palgrave/MacMillan, New York.

GeSI (2008) SMART 2020: enabling the low carbon economy in the information age. Available at: http://www.gesi.org/index.php?article id=43

Gibbons, M., Limoges, C., Nowotny, H., Schwartzman, S. Scott, P. \& Trow, M. (1994) The New Production of Knowledge: The Dynamics of Science and Research in Contemporary Societies. Sage, London.

Gough, S. \& Scott, W. (2008) Higher Education and Sustainable Development: Paradox and Possibility. Routledge, London.

Hansen, J.,Sato, M., Karecha, P., Beerling, D. Berner, R., Masson-Delmotte, V., Pagani, M., Raymo, M. Royer, D.L. \& Zachos, J.C. (2008) Target atmospheric CO2: Where should humanity aim? Open Science Atmospheric Journal. arXiv:0804.1135v3 [physics.ao-ph]

Homer-Dixon, T. (2002) The Ingenuity Gap. Vintage Books, New York.

Jenkins, H. (2007) Confronting the Challenges of Participatory Culture: Media education for the 21st Century. Chicago, The MacArthur Foundation. 
Levy, P. (1997) Collective Intelligence: Mankind's Emerging World in Cyberspace. Basic Books, New York,.

Maxwell, N. (2007) From Knowledge to Wisdom: the Need for an Academic Revolution. London Review of Education, vol.5, no.2, pp.97-115.

McCullough, M. (2004) Digital Ground: architecture, pervasive computing and environmental knowing. MIT Press, Cambridge Mass.

Middleton, J. (2007) Beyond Authority: Leadership in a Changing World. Palgrave/Macmillan, London.

Mihata, K. (1997) The Persistence of "Emergence" in Eve, R.A., Horsfall, S. \& Lee, M. E. Eds Chaos, Complexity and Sociology: myths, models and theories. Sage, London.

Mocigemba, D. (2006) Sustainable Computing. Poiesis Prax, Vol 4, pp.163-184.

Mocigemba, D. (2008) P4P - Podcasting for Participation. International Journal of Sustainability Communication, CCP 2, pp.3-21. Available at: http://www.ccponline.org/docs/artikel/02/02 mocigemba.pdf

Orr, D.W. (2006) Design at the Edge. MIT Press, Cambridge Mass.

Park, K.S, Leigh, J., Johnson, A., Carter, B., Brody, J., \& Sosnoski, J. (2001) "Distance Learning Classroom Using Virtual Harlem" in Proceedings of the Seventh International Conference on Virtual Systems and Multimedia (VSMM'01) pp.1289-1320..

Parry, R. (2007) Recoding the Museum: digital heritage and the technologies of change. London, Routledge.

Paterson, M. (2006) Feel the presence: technologies of touch and distance. Environment and Planning D: Society and Space, vol. 24, pp.691-708

Ratner, B.D. (2004) "Sustainability" as a Dialogue of Values: Challenges to the Sociology of Development. Sociological Inquiry, Vol. 74, No1, pp.59-69.

Register, R. (2006) Ecocities: Rebuilding Cities in Balance with Nature. Gabriola Island, New Society Publishers.

Revkin, A.C. (2007a) Be an Eco Sinner or Saint in the New SimCity "dot earth blog" New York Times, Nov 14, 2007, 5:49 PM. Available at:

http://dotearth.blogs.nytimes.com/2007/11/14/be-an-eco-sinner-or-saint-in-the-newsimcityl

Revkin, A.C. (2007b) Will Game's Impact Surpass 'Inconvenient Truth'? "dot earth blog" New York Times, Nov 15, 11:24 AM. Available at:

http://dotearth.blogs.nytimes.com/2007/11/15/will-games-impact-surpass-inconvenient$\underline{\text { truth/ }}$

Roy, R., Potter, S,. Yarrow, K. \& Smith, M. (2005) Towards Sustainable Higher Education: Environmental impacts of campus-based and distance higher education systems. Open 
University Design Innovation Group. Available at:

http://www3.open.ac.uk/events/3/2005331 47403 o1.pdf

Schneider, S.H. (2008) Geoengineering: could we or should we make it work? Philosophical Transactions of the Royal Society A. Available at:

http://journals.royalsociety.org/content/lnt0676gl7302372/?p=e876a5f2fd5e4b93a0b239845e4eb8c 1\&pi=1

Selby, D. (2007) As the heating happens: Education for Sustainable Development or Education for Sustainable Contraction? International Journal of Innovation and Sustainable Development, Vol.2, no.s 2/3,pp.249-267.

Sterling, S. (2001) Sustainable Education: revisioning learning and change. Green Books, Totnes.

Weinberger, D. (2002) Small Pieces Loosely Joined: a unified theory of the web. Basic Books, New York. 